\title{
Technology Development for Fire Safety in Exploration Spacecraft and Habitats
}

\author{
Gary A. Ruff ${ }^{1}$ and David L. Urban ${ }^{2}$ \\ NASA John H. Glenn Research Center, Cleveland, OH 44256
}

\begin{abstract}
Fire during an exploration mission far from Earth is a particularly critical risk for exploration vehicles and habitats. The Fire Prevention, Detection, and Suppression (FPDS) project is part of the Exploration Technology Development Program (ETDP) and has the goal to enhance crew health and safety on exploration missions by reducing the likelihood of a fire, or, if one does occur, minimizing the risk to the mission, crew, or system. Within the past year, the FPDS project has been formalized within the ETDP structure and has seen significant progress on its tasks in fire prevention, detection, and suppression. As requirements for Constellation vehicles and, specifically, the CEV have developed, the need for the FPDS technologies has become more apparent and we continue to make strides to infuse them into the Constellation architecture. This paper describes the current structure of the project within the ETDP and summarizes the significant programmatic activities. Major technical accomplishments are identified as are activities planned for FY07.
\end{abstract}

\section{Introduction and Background}

$\mathrm{T}$ The Vision for Space Exploration (VSE) announced by President George W. Bush on January 14, 2004 directed NASA to achieve the long-term goal of sending humans back to the Moon and then on to Mars. The extent of knowledge that must be gained and the number of technologies that must be developed before such missions can occur are certainly formidable. The performance standards required for these technologies are, in many cases, well beyond those used on the International Space Station and the Space Shuttle and will stretch our current knowledge of living and working in space. A large number of the challenges are related to ensuring the health and safety of the crew during the exploration mission.

The Fire Prevention, Detection, and Suppression (FPDS) project is a technology development effort within the Exploration Technology Development Program (ETDP) of the Exploration System Missions Directorate (ESMD) that addresses all aspects of fire safety aboard crewed exploration systems. The overarching goal for the FPDS project is to develop technologies that will ensure crew health and safety on exploration missions by reducing the likelihood of a fire, or, if one does occur, minimizing the risk to the crew, mission, or system. This is accomplished by addressing the areas of (1) fire prevention and material flammability, (2) fire signatures and detection, and (3) fire suppression and response. Much of this work had its origins in the Microgravity Combustion Science Program that began in the mid-1980's and funded peer-reviewed basic research in a broad range of topics in reduced-gravity combustion. ${ }^{1}$ In early 2000, the Bioastronautics Initiative provided funds to allow researchers in the Microgravity Combustion Science Program to begin to transition from basic research to more applied fire safety investigations although still through the peer-reviewed, NASA Research Announcement (NRA) process. The announcement of the VSE continued the transition to technology development projects with the FPDS project being formed shortly thereafter. The grants funded by the 2001 and 2002 combustion science NRA solicitations have either been continued in the FPDS project or allowed to end in FY06 at the completion of their funding. (In many cases, the projects were terminated after three years of funding, as directed by NASA HQ, instead of the normal four years.)

This paper identifies the deliverables for the FPDS project and discusses the status of the project. Even though the goals of the FPDS project have remained unchanged since its inception, it has undergone considerable review and revision as NASA implements the VSE, as has all the technology development projects. The status of the project was reviewed in January of $2005^{2}$ and $2006^{3}$ so this paper will focus on the programmatic activities and technical accomplishments over the last year for the current tasks within the FPDS project.

${ }^{1}$ FPDS Project Lead, NASA John H. Glenn Research Center/MS 77-7, AIAA Associate Fellow..

${ }^{2}$ Chief, Combustion and Reacting Systems Branch, NASA John H. Glenn Research Center/MS 77-5, AIAA Senior Member. 


\section{Project Description and Deliverables}

As previously stated, the goal for this work is to develop technologies that will ensure crew health and safety on exploration missions by reducing the likelihood of a fire, or, if one does occur, minimizing the risk to the crew, mission, or system. This may be accomplished by developing technologies that are applied during the design of the vehicle to eliminate or reduce the probability of a fire or by developing technologies to provide the crew with effective detection and suppression systems to minimize the impact on the spacecraft systems and mission success if a fire would occur. The technologies under development in the FPDS project are identified by a set of deliverables (or products) consisting of hardware, design requirements, data for trade studies, test procedures, data libraries, or recommendations for fire response procedures, depending on the application. For FPDS, the deliverables are:

Fire Prevention and Material Flammability

1. Definition and verification of a normal gravity material flammability test(s) to evaluate reduced gravity flammability

2. Assessments of material flammability in relevant cabin atmospheres and gravity levels for exploration transit vehicles and habitats

3. Definition and evaluation of realistic fire and fire response scenarios for exploration spacecraft and habitats

Fire Signatures and Detection

4. Advanced detection system for gaseous and particulate pre-fire and fire signatures

5. Verified models of the transport of contaminants, smoke, and combustion gases throughout the habitable volume of a spacecraft or habitat

Fire Suppression and Response

6. Design rules for suppressant system including effectiveness of suppressants, required concentrations, and dispersion methods

These were originally developed through a series of workshops that focused on spacecraft fire safety ${ }^{4-6}$ as well as previous studies and reports that have addressed fire protection in spacecraft. ${ }^{7-9}$ The most recent workshops were held in 2001, ${ }^{4} 2003,{ }^{5}$ and 2004; the first workshop was held in $1986 .{ }^{6}$ Given the changes that have occurred in NASA's exploration mission during this period, one might expect the FPDS deliverables to have changed significantly. Independent of the mission, NASA's basic philosophy to ensure fire safety on spacecraft has remained constant during this period and the FPDS deliverables are aligned with that philosophy. What has changed, however, is (1) the technology available to apply that philosophy, (2) the specific missions to which this technology is applied, and (3) our understanding of low-gravity phenomena related to fire safety. So, even though the deliverables are the same, the tasks to achieve these deliverables are constantly reviewed and revised as the technology needs change. In the remainder of the paper, the tasks are identified and briefly discussed with specific emphasis on noteworthy or timely accomplishments.

\section{Programmatic Considerations}

\section{A. Exploration Technology Development Program}

At the beginning of 2006, the Exploration Technology Development Program (ETDP) was still in the formulation process. As the program was defined, so were the requirements on the technology development projects. All projects conformed to new reporting and operational procedures aimed at providing uniformity in how technology was evaluated, developed and infused into the Constellation Program. This completed the transition from research-type projects to technology development that was begun with the announcement of the Vision for Space Exploration. One requirement was that every project formulate a project plan to outline the general direction and procedures for each project given the anticipated funding levels at the Spring 2006. The FPDS project plan, completed and signed in May 2006, developed the philosophy and major objectives of the tasks described in this paper. The second major programmatic accomplishment of the year was the successful completion of the Integrated Baseline Review (IBR). The purpose of the IBR, conducted by the ETDPO, was to review the detailed implementation plan for FY07 although major milestones for later years were also addressed. To prepare for this review, specific plans for each FPDS task were formulated including objectives, recent accomplishments, FY07 milestones, budget, and implementation plan for the assessment of Earned Value. The FPDS review was completed in October 2006 and this paper summarizes much of the content presented in the IBR. Interestingly, planning for the 
IBR by the entire FPDS team provided a framework for all team members to plan their work for the year and become more familiar with the overall objectives of the FPDS project.

\section{B. Constellation and CEV Program Requirements Formulation}

The continued maturation and activities of the Constellation and CEV Program Offices has had the largest programmatic impact on the FPDS during the year. The Constellation Program Office (CxPO) initiated Level II activities by forming various Systems Integration Groups (SIGs) that are the "owners" of the Constellation Requirements for that discipline. The fire detection and suppression function on a spacecraft is part of the Environmental Control and Life Support (ECLS) system and, as such, is included in the ECLS-Thermal SIG, led by Robyn Carrasquillo of NASA Marshall Space Flight Center and John Lewis of NASA Johnson Space Center. The SIG activity that has most impacted the FPDS project has been the formulation of the fire detection and suppression (FDS) requirements in the Constellation Architecture Requirements Document (CARD) and the Human Systems Integration Requirements (HSIR). While the Level II requirements are at a fairly high level, the requirements formulation process prompted many discussions about the philosophy of fire detection and suppression to be used on Constellation vehicles and, therefore, helped confirm and guide FPDS tasks.

The CEV (now called Orion) Project Office was also set up during this year. The development of the vehicle Level III requirements further helped to refine the fire detection and suppression requirements for CEV. The selection of a prime contractor for Orion made discussions of the fire detection and suppression systems more concrete as the differences between the NASA and contractor designs were debated and resolved. While the design is still in flux, the FPDS tasks have remained important and relevant to the development of the Orion spacecraft.

\section{Implementation}

The FPDS project is led by the NASA Glenn Research Center and several teams have been formed to implement tasks in areas of material flammability, fire detection, and fire suppression. The Flammability Research Team, led by Dr. Fletcher Miller, monitors and implements the tasks in the area of fire prevention and material flammability. Similarly, Dr. Daniel Dietrich leads the Fire Suppression and Response Research Team. Because of synergy with the Environmental Monitoring and Control project and the recently formulated "Dust" project, the Fire Signature and Detection Research Team is co-led by Dr. David G. Fischer and the authors. These teams defined the tasks to be discussed in the next section, developed work schedules and defined appropriate milestones that will be used to implement Earned Value Management for this project.

\section{Description and Status}

Considerable progress has been made toward the stated FPDS deliverables in the past year. Even with the programmatic uncertainties, the FPDS scientists and technicians are entering 2007 with a clear direction on the objectives and requirements for each task. In this section, each of the major tasks in FPDS are briefly described along with the current status and plans for the coming year. Particular emphasis will to given to those tasks with noteworthy or timely accomplishments. The deliverables addressed by each task are also noted in parentheses because there if not always a one-to-one correspondence and several tasks can contribute to a single deliverable.

\section{A. Fire Prevention and Material Flammability}

1. Normal Gravity Flammability Test (Deliverable 1)

One of the deliverables of the FPDS project is a methodology by which the low-gravity flammability of a material can be determined based on a test conducted in normal gravity. Currently, two general approaches to achieve this deliverable are being investigated. The first approach is to define a normal-gravity test configuration such that the effect of buoyancy on the flame behavior is minimized. In the second approach, specific flammability properties of the material are measured in the presence of buoyancy and the low-gravity behavior is determined from the measured values of these properties. Three tasks within the FPDS project follow one of these two approaches and are discussed later in this paper (Section IV.A., sub-sections 2, 3, and 4).

Even while the test methods are being developed, we must remain focused on the infusion of this technology as a NASA standard test. Through our work with the NASA-STD-6001 Topical Working Group, it has become clear that even if a test exists that yields a quantitative measure of low-gravity flammability, it might not be acceptable as a standardized test. Other factors must be considered and, depending on the test, may become obstacles to that test ever being adopted. We developed a working list of these requirements, shown in Table 1, to help guide our Team in the formulation of topics that must be addressed for each of the proposed methods. 
Table 1. Criteria for Acceptance of a Material Flammability Test Method

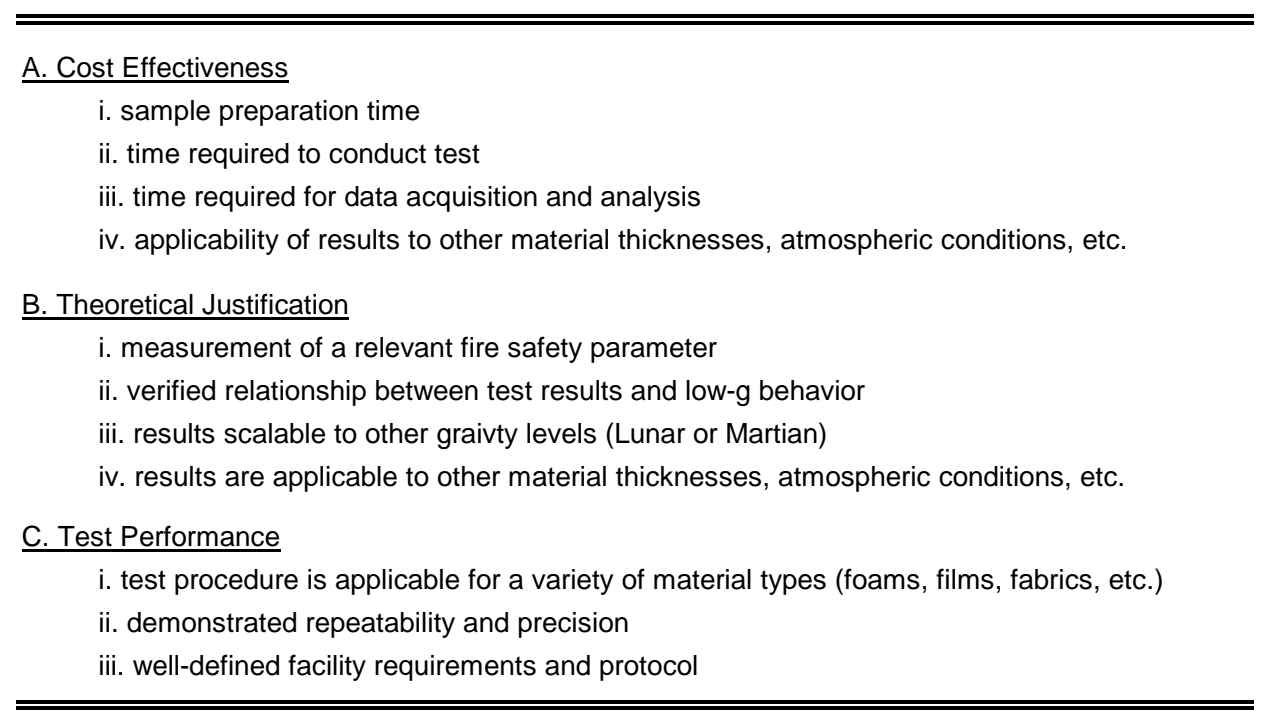

There are no specific weighting factors or rankings by which these requirements can be used to compare two or more test methods. Instead, these are more useful as "go/no-go" requirements that could identify a potential obstacle for a specific method. For example, NASA-STD-6001 Test 1 is NASA's primary material flammability screening test $^{10}$ and it is useful to subject this test to these criteria. Test 1 is frequently criticized from microgravity combustion science and fire safety community because its lack of a theoretical justification and connection to low-gravity flammability. In defense of the test, upward flame spread is generally a "worst-case" flame spread condition and the igniter used in the test is considered to be more energetic that spacecraft ignition sources. Therefore, even though the low-gravity justification for this test may be lacking, the test is assumed to be conservative. Also, over the years, the cost effectiveness and the test performance has been demonstrated to be quite acceptable. Therefore, while scientists in the FPDS project frequently focus on tests that have a strong theoretical justification, we must remember that the test should not impose a significant burden in either cost or time from any combination of test time, sample preparation, specialized facilities, data analysis, etc. Therefore, in addition to continuing the technical justification of these methods, work is being conducted on all of the proposed test methods to evaluate the broad range of requirements listed in Table 1 during FY07. This will lead to a formal evaluation and down-select at the end of the fiscal year with only the most promising method or methods continuing development into FY08 and beyond.

\section{Forced Ignition and Spread Test (FIST) - (Deliverable 1)}

One of the test methods being considered as a standardized test is the Forced Ignition and Spread Test (FIST) (PI: Prof. C. Fernandez-Pello, University of California - Berkeley). The general approach applied in this method is to measure standard material flammability characteristics and then perform engineering calculations, including computer fire modeling, to calculate the impact of various fire scenarios on the spacecraft under consideration. The FIST apparatus, shown in Fig. 1 and described by Cordova et al. ${ }^{11}$, is a small-scale wind tunnel with the sample material mounted flush to the bottom wall of the tunnel and irradiated by heaters in the upper wall of the duct. The radiant heaters are designed to provide a spatially-varying radiant flux that is highest at the downstream end of the sample and decreases along its length. The data obtained from the FIST apparatus can be plotted as a 'flammability diagram' that shows the ignition time and flame spread rate as a function of the external heat flux. The critical heat flux for ignition given can also be determined from the test data. The primary significance of the test method is that material flammability properties such as the apparent thermal inertia, effective ignition temperature, and flame spread parameters can be determined by correlating the flame spread and ignition delay branches of the diagram with a theoretical model (analytical or numerical). Using this information, materials can be ranked based on their readiness for piloted ignition, susceptibility to flame spread, and extinction characteristics.

FIST researchers have been investigating both experimentally and computationally the critical mass-loss rate required for a sample to ignite. This could prove to be a flammability acceptance criterion for this test. Planned tasks for FY07 include developing the capability to conduct tests in exploration atmospheres (up to $36 \% \mathrm{O}_{2}$ and 
approximately 7 psia), and verifying the test protocol. In the computational analysis, they will complete the solid phase model and use it to investigate the effect of oxygen concentration and gravity on the results.
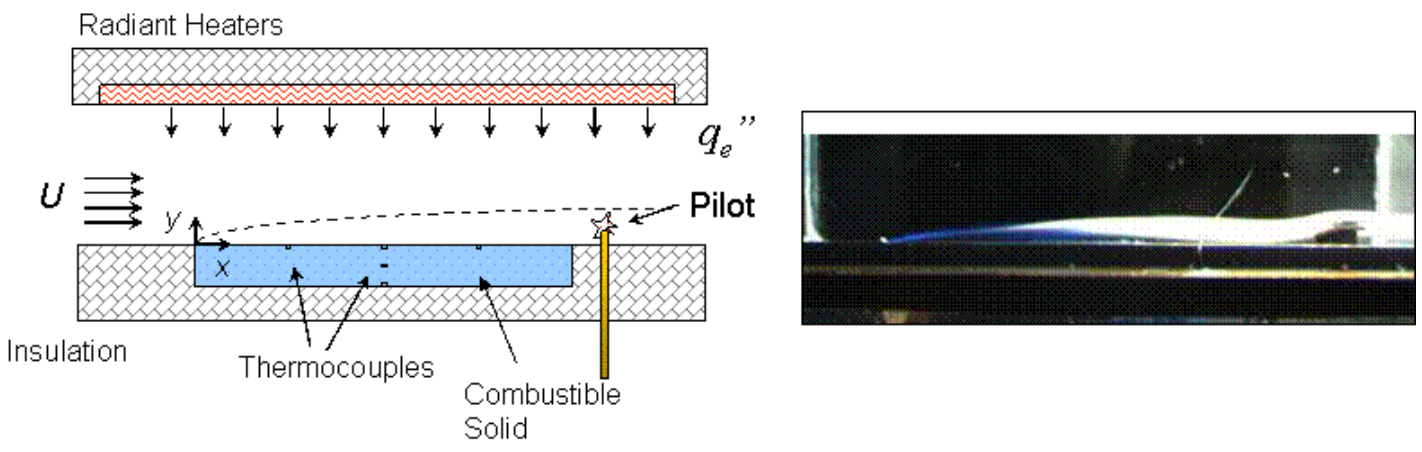

Figure 1. Forced Ignition and Spread Test (FIST) experimental apparatus and typical flame. $A$ schematic of the FIST apparatus is shown in the left-hand image while a side-view of a typical flame is shown on the right. The blue flame is visible at the upstream portion of the sample with a smoke trail extending over the igniter on the right.

\section{Low Stretch Scaling (Deliverable 1)}

Unlike the FIST apparatus discussed above, the Equivalent Low-Stretch Apparatus (ELSA) uses an experimental configuration in which buoyancy is suppressed (PI: Dr. S. L. Olson, NASA GRC). The configuration and test techniques of the ELSA test are similar to a cone calorimeter test except that the sample is burned above the radiant heater as shown in Fig. $2 .^{12}$ In this configuration, the velocity gradient normal to the flame sheet is largely determined by the velocity of the incoming flow rather than buoyancy. The hypothesis is that this "low-stretch" flame shares many features with a low-gravity flame frequently characterized by low stretch rates because of the lack of buoyancy. However, the concept of low-stretch scaling places fairly strict requirements on the flow field in the apparatus which can be perturbed by the interaction of the incoming flow, radiant heater, and burning sample. In FY06, smoke flow visualization was used to observe the flow in the apparatus and, as a result, a new nozzle was fabricated and installed. A modeling effort using both the Fire Dynamic Simulator and FLUENT computational codes was begun to investigate the details of the ELSA flow field and the low-stretch scaling assumptions. A Particle Image Velocimetry (PIV) system is being set up to obtain quantitative measurements of the flow field that will be compared to the numerical results. Recently, tests have been performed on various materials such as Combitherm ${ }^{\mathrm{TM}}$, Kevlar ${ }^{\mathrm{TM}}$, Nomex ${ }^{\mathrm{TM}}$, Pyrell ${ }^{\mathrm{TM}}$ foam, and $\mathrm{Kydex}^{\mathrm{TM}}$ to evaluate the suitability of this test for a range of materials. No significant difficulties in testing these materials have been identified. Both the modeling and experimental verification tests will continue in FY07.

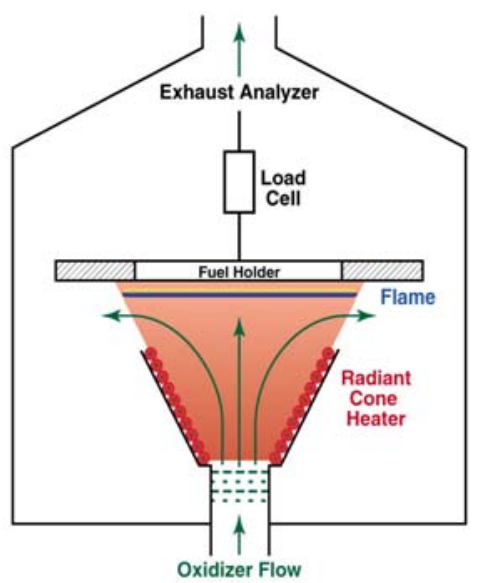

Figure 2. Sketch of the Equivalent Low-Stretch Apparatus (ELSA).

\section{Sub-critical Rayleigh Number Analogy (Deliverable 1)}

While the ELSA configuration suppresses buoyancy by burning the sample in a ceiling configuration, another way to suppress buoyant convection is to burn the sample between two plates separated by a small distance. The plate separation is determined from the Rayleigh number defined as the ratio of the buoyant to viscous forces in a fluid and given by the equation

$$
R a=\frac{g \beta\left(T_{1}-T_{2}\right) L^{3}}{\alpha v}
$$


where $g$ is the gravitational acceleration, $\beta$ is the coefficient of thermal expansion, $\mathrm{L}$ is the characteristic length, $\alpha$ is the thermal diffusivity, and $v$ is kinematic viscosity. $\mathrm{T}_{1}$ and $\mathrm{T}_{2}$ are the temperatures of the lower (heated) and upper plates, respectively. For Rayleigh numbers less than a critical value, buoyancy forces cannot overcome the resistance imposed by the viscous forces and there is no buoyancy-driven convection within the cavity thereby simulating a low-g environment. For horizontal plates heated from below, the value of the critical Rayleigh number is approximately $1708 .{ }^{13}$ Using $\mathrm{T}_{1}=900 \operatorname{deg} \mathrm{C}$ and $\mathrm{T}_{2}=80 \operatorname{deg} \mathrm{C}$, the plate separation distance, $\mathrm{L}$, that yields $R a_{c}=1708$ is $1.1 \mathrm{~cm}$. Accordingly, the plate separation typically used in the Narrow Channel Facility is $1.0 \mathrm{~cm}$ configuration.

The Narrow Channel Facility can measure the flame spread rate and the propensity for flame propagation at a specific flow velocity, pressure, and oxygen concentration ${ }^{14}$ (PI: Dr. F. J. Miller, National Center for Space Exploration Research (NCSER)). The primary question being examined at this time is whether the distance between the plates can be standardized for most samples or whether it must be determined for each type of material to be tested. Also, FPDS scientists have recently investigated whether the flame spread rate can be determined as a function of flow velocity in a single test by slowly decreasing the flow velocity (approx. $2 \mathrm{~cm} / \mathrm{s}^{2}$ ) rather than by conducting multiple, constant velocity tests. Although still under investigation, the results to date have been promising. Given the results of these tests, the facility is being modified so that the oxygen concentration can be slowly decreased during a test to determine the minimum oxygen concentration for flame spread. Other aspects of this test that will be evaluated in FY07 include the effectiveness of the test to evaluate concurrent (upward) flame spread, the burning of thick materials, and the impact of heat loss to the walls on the test results.

\section{Evaluation of NASA-STD-6001 Test 1(Deliverables 1 and 2)}

Recently, Quintier ${ }^{15}$ has made use of flammability parameters defined by Tewarson ${ }^{16}$ to develop a theoretical formulation for fire growth processes such as ignition, burning and energy release rate, and flame spread under external radiant heating. More significantly, however, this formalism also identifies critical conditions that can limit these processes. The methodology has been demonstrated using data obtained from the Room Corner Test (ISO 54) for a variety of materials and a similar type of analysis will be performed for NASA-STD-6001 Test 1 . For example, NASA-STD-6001 Test 1 can be thought of as a sequence of several types of flammability tests. First, it is an ignition test using a specific external heating profile produced by the igniter. If the material ignites, it then becomes a flame propagation test first with the igniter on but after $25 \mathrm{sec}$ (the approximate time the igniter is on) with the only energy input provided by the flame itself. Of course, a material fails Test 1 if the flame propagates more that 15 $\mathrm{cm}$ (6 inches). If this formalism can developed to define critical values of the flammability parameters that dictate whether these processes can occur for this test, a firm connection can be made between NASA's existing test and other standard material flammability tests, including those under development to determine low-gravity flammability. Maintaining a connection to the existing material flammability database (MAPTIS ${ }^{17}$ ) while supplying additional information about low-gravity flammability would significantly increase NASA's ability to assess flammability risks during future exploration missions.

\section{Pressure-Gravity Scaling (Deliverable 1 and 2)}

The previous tasks were aimed at developing test methods that could be used to assess low-g material flammability. While these methods could potentially be applied to partial-gravity applications, our understanding of material flammability in partial gravity is even less than that in low (near zero) gravity. Test results have shown that flammability limits, i.e., oxygen concentrations that support combustion are not simple interpolations between low-g and normal-g. ${ }^{18}$ Therefore, two FPDS tasks are aimed at developing test techniques that could be used evaluate partial-g flammability or provide data to verify the performance of the low-g test methodologies previously described for partial-gravity applications. Feier et al. ${ }^{19}$ and Kleinhenz ${ }^{20}$ have investigated methods to scale results from upward flame spread experiments conducted at reduced pressures to upward flame spread rates in partial gravity. This technique, called Grashof number (or $\mathrm{P}^{2}$-g) scaling, has been demonstrated with good success by comparing test results in normal gravity with those obtained at Lunar and Martian gravity levels on the C-9 aircraft. Figure 3a shows images of upward flame spread on a 1-cm-wide paper sample at Lunar, Martian, and Earth gravity. When the pressure is increased to compensate for the reduced gravity, the three flames appear very similar, as shown in Fig. 3b. Figure 4 shows the flame spread rates measured under these conditions unscaled as a function of pressure (Fig. 4a) and as a function of the scaled variable $\mathrm{gP}^{1.8}$ (Fig. 4b). The correlation is seen to be excellent and demonstrates that the partial gravity flame spread rate can be scaled in this manner. Additional tests will be conducted in FY07 to verify this behavior for larger samples, i.e., having the same dimensions as those used in NASA-STD-6001 Test 1 (5 cm wide x $30 \mathrm{~cm}$ long of varying thickness) (co-I: Dr. Z.-G. Yuan, NCSER and Dr. J. E. Kleinhenz, Case Western Reserve University (CWRU)). 


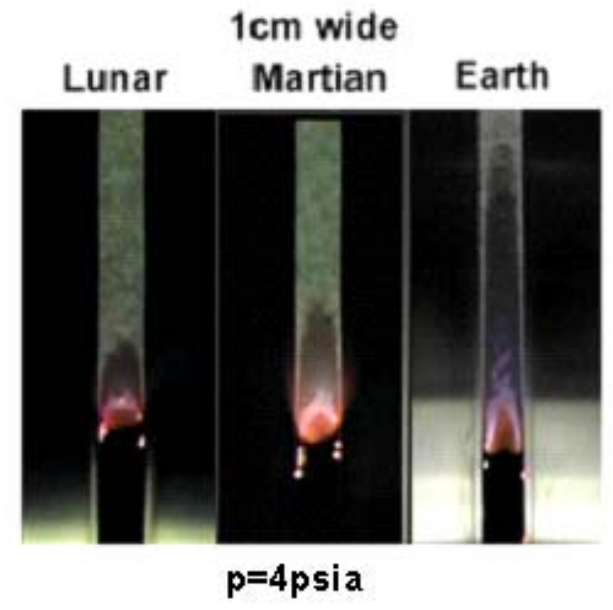

a. Upward flame spread at constant pressure at Lunar, Martian, and Earth normal gravity. Note the difference in burn length and flame appearance.

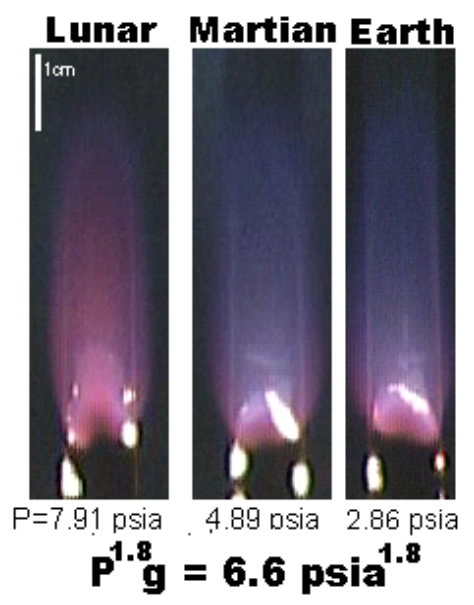

b. Upward flame spread at constant $\mathrm{P}^{1.8} \mathrm{~g}$. The burn length and flame appearance are quite similar when the scaling is applied..

Figure 3. Comparison of burn length and flame appearance with and without $\mathbf{P}^{2}$-g scaling.

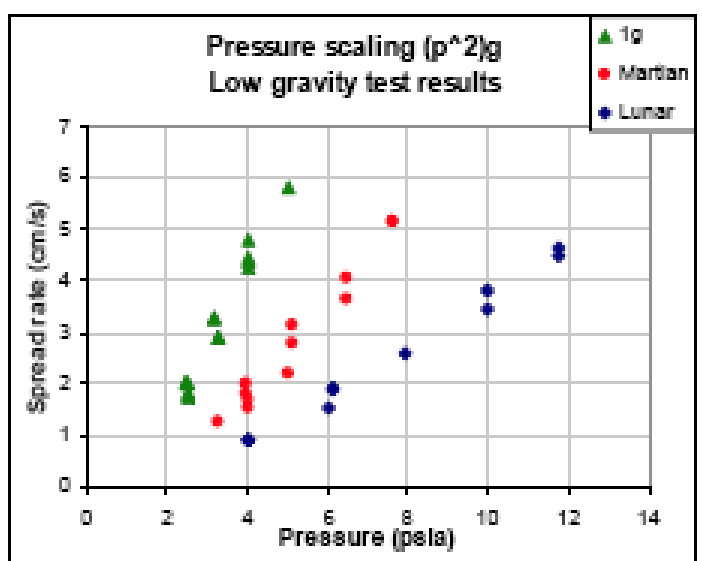

a. Upward flame spread rate at constant pressure at Lunar, Martian, and Earth normal gravity.

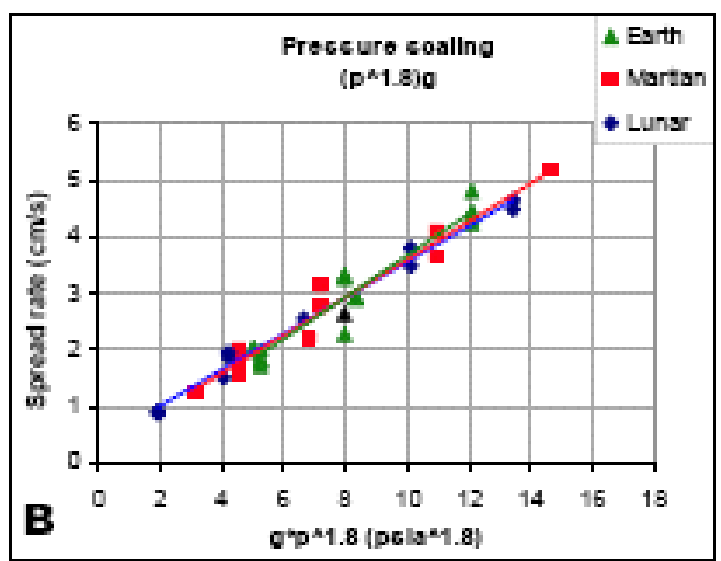

b. Upward flame spread rate correlation using constant $\mathrm{P}^{1.8} \mathrm{~g}$.

Figure 4. Correlation of upward flame spread rate using $\mathbf{P}^{2}$-g scaling

\section{Partial-Gravity Centrifuge (Deliverable 1 and 2)}

To date, all tests of partial gravity material flammability have been conducted on NASA's Reduced Gravity Aircraft flying the appropriate trajectory. Since clean low-gravity conditions are produced in drop towers at NASA Glenn Research Center, partial gravity could be achieved by placing a test sample on a centrifuge inside a drop rig and applying the appropriate rotational velocity. In FY06, the mechanical design for a centrifuge drop tower rig was completed and the components were assembled on a drop bus to be used in the Zero Gravity Facility at NASA GRC (co-I: Dr. P. V. Ferkul, NCSER, Dr. K. R. Sacksteder, NASA GRC, and Prof. J. S. T'ien, CWRU). Later in FY07, the rig will be wired and the check-out drops will be conducted. There are many questions to be answered about flammability tests conducted in a centrifuge and this task will provide some needed proof-of-concept data to determine if this is a practical tool for NASA to use to assess material flammability on the Lunar and Martian surface as its exploration missions continue. 


\section{Low-g Flammability in Exploration Atmospheres (Deliverable 2 and 3)}

The atmosphere of previous spacecraft has ranged from $100 \% \mathrm{O}_{2}, 34.5 \mathrm{kPa}$ for Mercury, Gemini, and Apollo missions to standard air (21\% $\left.\mathrm{O}_{2} / 79 \% \mathrm{~N}_{2}, 1 \mathrm{~atm}\right)$ for ISS and STS. (Atmospheric conditions prior to EVA are different from the standard cabin atmosphere.) These design points are shown in Fig. 5 and generally lie along the normoxic equivalent line, i.e., having the same $\mathrm{O}_{2}$ partial pressure as $100 \mathrm{kPa}, 21 \% \mathrm{O}_{2}$ by volume. ${ }^{21}$ In order to maintain $\mathrm{O}_{2}$ partial pressure along the normoxic line, the $\% \mathrm{O}_{2}$ increases as the total pressure decreases. Yet, it is the mole fraction of oxygen that affects the flammability of materials. The increased flammability of materials in these conditions is critical in terms of fire initiation, propagation, and suppression. In June 2006, the ECLSThermal SIG recommended to the Constellation Systems Engineering Control Board (ECB) a set of atmospheres for the habitable volume of the CEV and future exploration vehicles along with an operational philosophy of how the atmosphere could be varied depending on mission destination and objectives.

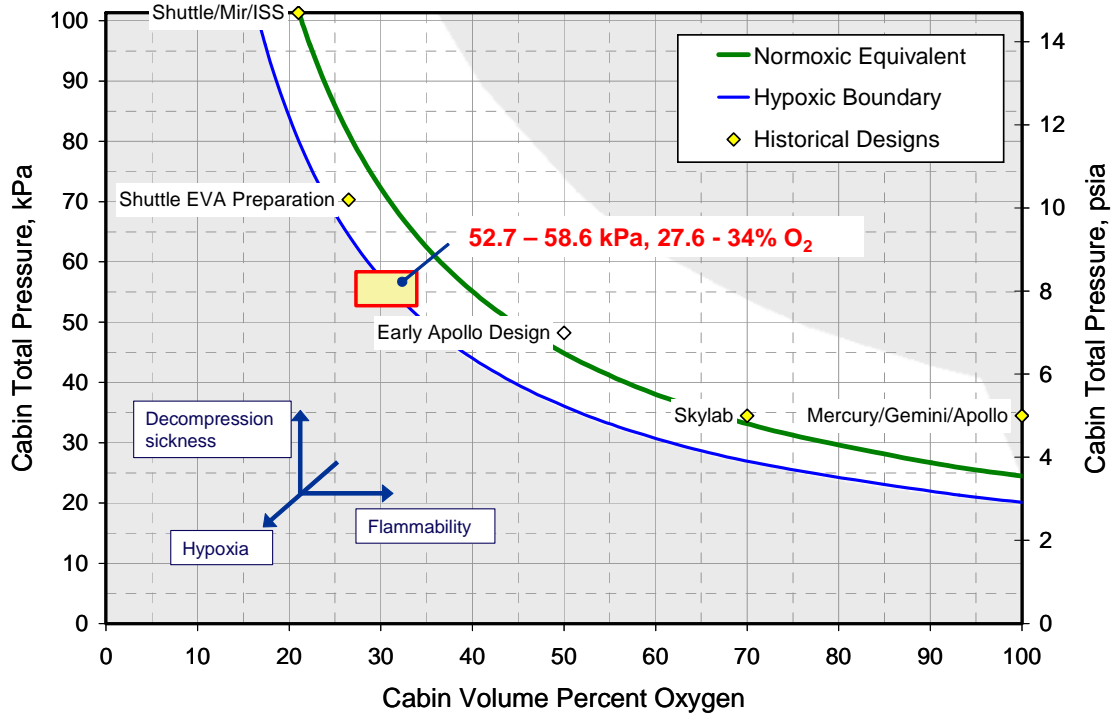

Figure 5. Design space for cabin atmosphere pressure and $\mathrm{O}_{2}$ concentration. Arrows indicate the trends for increasing risk of decompression sickness as a result of EVA, hypoxia, and flammability. ${ }^{21}$

The Board recommended that additional material flammability testing be performed to verify assumptions about the difficulty of certifying material flammability at increased oxygen concentrations. Specifically, NASA White Sands Test Facility would conduct NASA-STD-6001 Test 1 at an ambient pressure of 10.2 psia and a range of oxygen concentrations to identify the maximum oxygen concentration (MOC) for which the material passes Test 1 . For these initial tests, approximately 50 materials would be evaluated. Also included in this test program was a series of tests to be conducted in the Zero-Gravity Facility at NASA GRC to determine whether the MOC obtained in lowgravity was different than that obtained in the normal gravity test. Previous research has shown that a flame can be sustained at lower oxygen concentrations in low-gravity when buoyancy is eliminated and the convective velocity is less than that imposed by buoyant convection. ${ }^{22}$ A significant difference $\left(>1-2 \% \mathrm{O}_{2}\right)$ between the low- and normal gravity limits could change the habitable atmosphere recommendations. In fact, even prior to the request by the Constellation ECB, these tests were a part of the FPDS technology development project because this low-g data is required for verification of the normal gravity flammability tests methods previously discussed (co-I: Dr. S. L. Olson, NASA GRC and F. J. Miller, NCSER).

The ZGF drop rig to conduct these tests has been completed and the initial drops were conducted in December 2006. The oxygen threshold tests will begin early in FY07 after a short period of rig check-out and development of the test procedure. This round of tests will be completed no later than September 2007.

\section{B. Fire Signatures and Detection}

\section{Gas and Particulate Sensor Development (Deliverable 4)}

Smoke detectors on the ISS have proven to be sensitive to dust and have produced numerous false alarms. For this reason and other design constraints that will be imposed on future spacecraft, there is a need for new fire detector technology that eliminates nuisance alarms yet provides early pre-fire warning. The state-of-the-art in fire detection combines gaseous and particulate sensors into a hybrid fire detection system. Since 2001, the FPDS project has funded (along with other sources) the development of a sensor suite that couples solid state sensors for CO, $\mathrm{CO}_{2}, \mathrm{H}_{2}$, total hydrocarbons, and humidity with a particulate sensor (co-I: Dr. G. W. Hunter and Dr. P. S. Greenberg, NASA GRC). This hybrid detector has proven to have very good nuisance source discrimination while 
correctly identifying fires from a variety of fire sources. A newly-developed scattering sensor for particulate monitoring is being developed and will replace the particulate sensor in this suite.

As a result of several Technical Interchange Meetings (TIMs) between NASA and NASA/CEV contractor personnel, a set of requirements, shown in Table 2, were drafted to guide the development of these sensors in FY07 and beyond. These requirements are not reflected in an official CxP or Orion requirements document (yet) but they help to define desired detector operating characteristics, design parameters, and required testing so that sensor development can proceed. Both the gaseous and particulate detectors are on a path to produce an advanced fire detector by the end of FY07. A portion of the verification testing will be completed by that time with a more detailed assessment to be completed in FY08.

\section{Table 2. Working Requirements for Spacecraft Fire Detector}

\begin{tabular}{l} 
1. Time correlated detection of the presence of particulate and gaseous pre-fire and fire species. At a minimum, CO \\
should be detected; other species if required to demonstrate reliability, reduce nuisance alarms, etc. \\
2. Respond to particles in the range of $0.5-4$ microns and ignore particles having larger diameters \\
3. Sample particles at ambient flow velocities ranging from $5-15 \mathrm{~cm} / \mathrm{s}$ with the flow direction within 35 deg of normal \\
4. Detector should be able to operate continuously for no less than 6 months \\
5. Tolerant of expected cabin dust levels on the moon and ISS \\
6. Tolerant of vacuum cycles (unpowered) \\
7. Operates at ambient pressures from 1 atm to 8 psia \\
8. Capable of passing typical spacecraft noise, power, EMl, and thermal testing \\
9. Tolerant of nuisance sources including but not limited to lunar dust, spacecraft dust (hair, skin cells, fabric threads, \\
10. Sampling rate of $1 \mathrm{~Hz}$ \\
11. Able to achieve $80 \%$ of full-scale in $1 \mathrm{sec}$ when challenged with an appropriate full-scale source. \\
12. Alarm levels $\left(\sim 10^{6}\right.$ particles/cc or $\left.2 \mathrm{mg} / \mathrm{m}^{3}\right)$, Species levels TBD \\
\hline \hline
\end{tabular}

\section{Quantification of Fire Signatures (Deliverable 4)}

Even the best sensors won't detect a fire unless they are in a proper location and have been set to the appropriate alarm levels. Working together, they can effectively provide early fire detection as well as reliably identify nuisance sources. Therefore, while developing these sensors, there is a need to (1) quantify the gaseous and particulate fire signatures from common spacecraft materials and (2) test the sensors under pre-fire conditions with these materials. A ground-based facility has been developed to evaluate gaseous fire signatures from various materials using a variety of analytical techniques (PI: Dr. R. L. VanderWal, NCSER). In this facility, shown in Fig. 6, a sample is drawn into a furnace that has been pre-heated to a desired temperature. Light gases such as $\mathrm{H}_{2}, \mathrm{O}_{2}, \mathrm{~N}_{2}, \mathrm{CO}, \mathrm{CO}_{2}, \mathrm{CH}_{2}$ that are evolved are quantified by gas chromatography and mass spectrometry. Condensibles and particulate are collected using an adsorption column and filter, respectively and undergo analysis as desired. Initial tests on the sensor suite discussed in the previous section have been conducted in this apparatus and these tests will continue in FY07.

TGA-FTIR analysis has

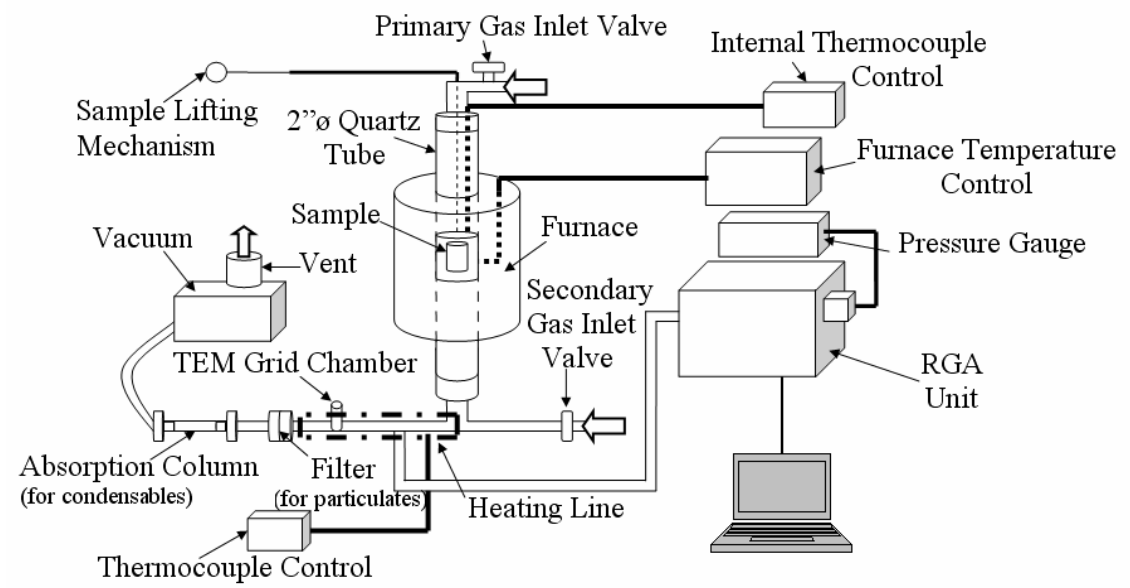

Figure 6. Schematic of the facility to evaluate fire signatures and advanced fire detection technologies 
been used with these samples to identify the gases evolved during smoldering and flaming combustion. The samples that are being evaluated include cotton, Kapton ${ }^{\mathrm{TM}}$, Teflon ${ }^{\mathrm{TM}}$, silicone rubber, Kevlar ${ }^{\mathrm{TM}}$, polyimide, melamine, and polyurethane foams, and Halar ${ }^{\mathrm{TM}}$ and Viton ${ }^{\mathrm{TM}}$ wire insulation. Tasks to be conducted in FY07 include (1) continuing the quantification of fire signatures using the assembled diagnostics, (2) preparation of a final report on the findings of the fire signature studies, and (3) evaluation of prototype gaseous fire detectors. Task (3) will provide an early indication of fire detector performance and develop the protocol for the general testing and evaluation of potential fire detectors for use on the CEV and LSAM.

While no longer a formal part of the FPDS project, the Smoke Aerosol Measurement Experiment (SAME), an experiment is an essential component of the fire signatures and detection technology area. The objective of the Smoke Aerosol Measurement Experiment (SAME) (PI: Dr. David L. Urban, NASA GRC) is to conduct a test in the ISS Microgravity Science Glovebox to provide in situ particle size information for several smoke aerosols (solid and liquid). ${ }^{23}$ This data will quantify the particulate pre-fire signatures of relevant spacecraft materials (Kapton ${ }^{\mathrm{TM}}$ and Teflon $^{\mathrm{TM}}$, for example) and be used to guide the development of improved smoke detectors. The SAME experiment is currently scheduled for Flight Hardware Availability in February of 2007 and launch aboard STS 13A.1 later in 2007.

\section{Modeling of Smoke and Contaminant Transport (Deliverable 3)}

The effectiveness of even the most refined fire detector will be reduced unless it is located in the right place and the time required for the contaminant to reach a detectable level at that location is known. The objective of this task is to develop the tools and methodology to evaluate fire detector placement and time-to-alarm for a given spacecraft geometry. (PI: J. E. Brooker, NASA GRC) In the absence of a sufficiently detailed design for the CEV, work has focused on analyzing smoke transport and smoke detector activation in the Destiny module of the ISS. The module dimensions, vent locations, and flow rates were obtained from ISS documentation and conversations with ISS Environmental Control and Life Support System (ECLSS) personnel. Obstructions in the module were estimated from recent ISS photographs. As shown in Fig. 7, the six air supply diffusers within the module are positioned such that the flow is across the ceiling and down the port wall establishing a rotational flow pattern (counter-clockwise facing forward). Two IMV diffusers (one aft-port, the other forward-starboard) direct flow along the floor in the forward and aft directions. For this simulation, smoke sources were modeled as soot-emitting propane burner with a fixed heat flux and located at the center of each Integrated Standard Payload Rack (ISPR). Circumferential profiles of detection time were constructed by moving the smoke source around the module on each of the four walls. The strength of the smoke source was varied to determine the effect of smoke source on alarm time.

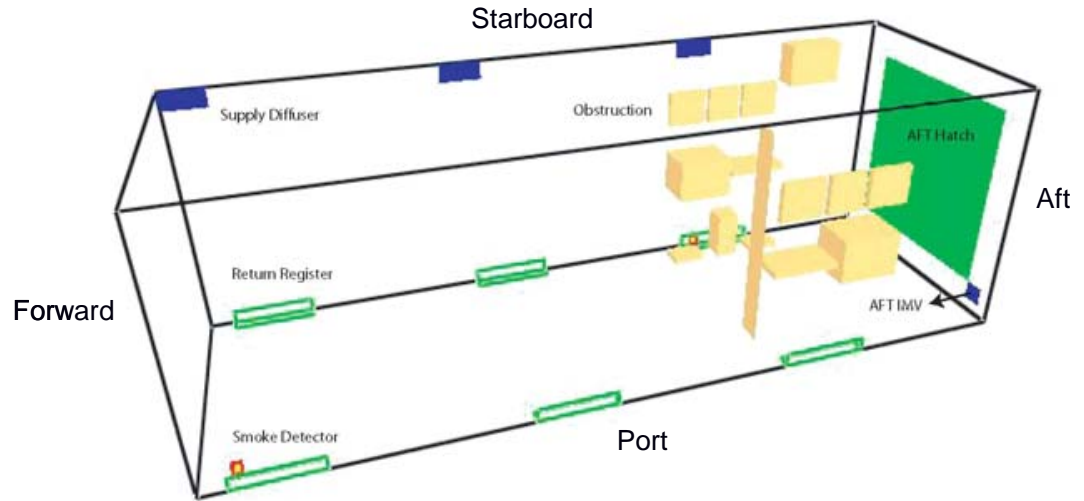

Figure 7. Geometry of the ISS Destiny Module used for the smoke detector evaluation. Supply diffusers are on the upper wall (blue) and the return registers are on the floor (green)

Typical variations in the timeto-alarm as a function of location of the smoke source are shown in Fig. 8. The shortest alarm time resulted when both IMV flows were present and there were no obstructions (red bars). The transport of smoke along the length of the module is reduced when the forward IMV flow is removed making the results more dependent on the location of the smoke source and the presence of obstructions. For these conditions, the time-to-alarm varied from about 15 sec to approximately 90 sec. The time-to-alarm increased significantly as weaker smoke sources were used. In addition to determining the proper location for fire detectors, this tool is useful to analyze potential fire and fire response scenarios (Deliverable 3). The analysis for the Destiny Lab Module will continue in FY07 culminating in a comprehensive report of the results. As the CEV design develops, a similar analysis will be initiated for this vehicle. 


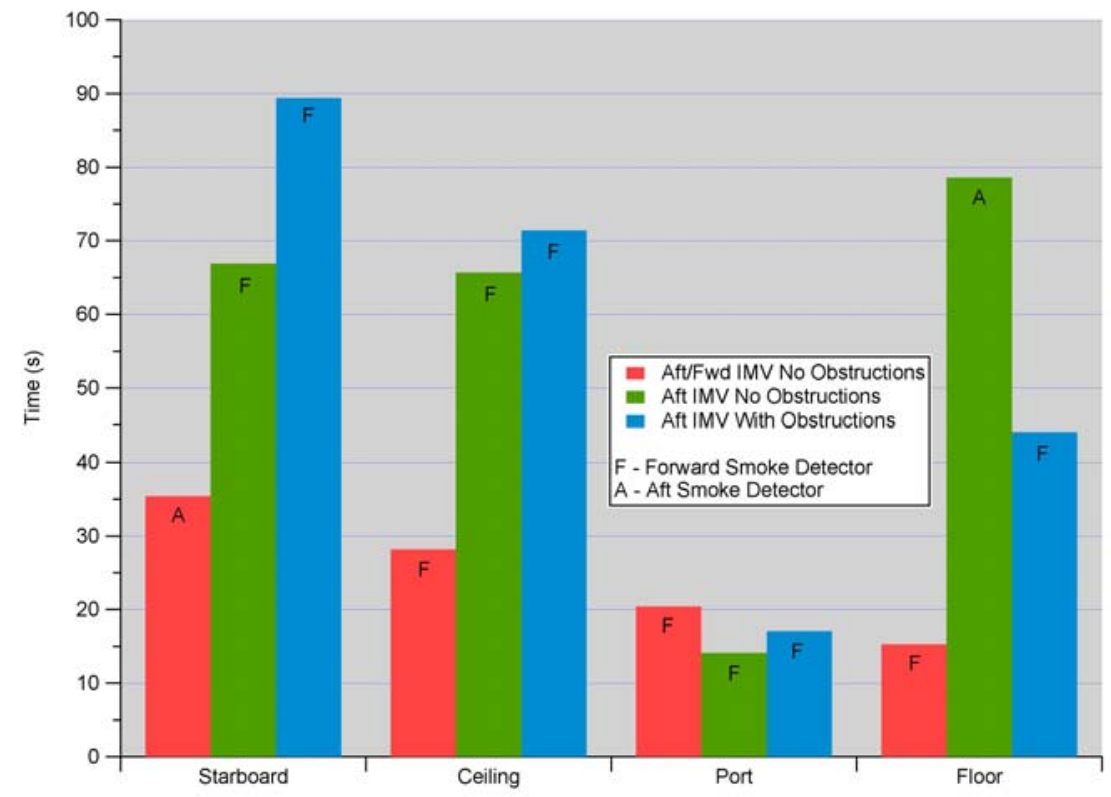

Figure 8. Typical results of the smoke detector activation modeling in the ISS Destiny module.

\section{Fire Suppression and Response}

NASA's design philosophy is to control ignition sources and material usage so that the likelihood of a fire on a spacecraft is very small. However, because the potential impact of a fire on the mission and safety of the crew, methods for fire suppression are always provided. Worse than not having a fire extinguisher on board is having one that is ineffective at extinguishing the types of fires that may be experienced or that behaves unexpectedly in low-g so as to render it ineffective. The objective of the tasks in this area is to develop the data and experience with various suppressants and suppressant systems to ensure they will perform as expected if ever needed.

\section{Effectiveness of Fire Suppressants in Low-g (Deliverable 5)}

The objective of this task is to quantify the effectiveness of candidate suppressants in reduced gravity. Surprisingly, one of the primary issues facing the fire suppression and response technology development area is to determine the proper suppression agents to investigate. There are many different agents and methods that could be used to extinguish a fire depending on the type of material burning, the ambient atmosphere, and the volume of the spacecraft, to name a few. The variation in suppression effectiveness with these variables can range from being slightly less effective that it could be to becoming completely ineffective. In fact, the use of an inappropriate suppression agent might even produce a more harmful environment for the crew. The parameters and characteristics that will constrain the selection of a fire suppression agent depend on CEV design parameters that are only now becoming more firm and will be incorporated into our tasks as they become known.

Because gaseous $\mathrm{CO}_{2}$ was used as the fire suppression agent on the ISS, recent studies have focused on understanding the relative effectiveness and quantifying the minimum extinction concentration for passive gaseous suppression agents, such as $\mathrm{CO}_{2}, \mathrm{~N}_{2}, \mathrm{Ar}$, and $\mathrm{He}$. In these investigations, various experimental configurations are being used including opposed-flow diffusion flames, ${ }^{24}$ cup burners, ${ }^{25-27}$ and PMMA cylinders. ${ }^{28}$ Several of these studies are continuing and new ground-based and low-g data are still being analyzed. Two significant issues are that (1) the studies have been performed in NASA's Reduced Gravity Aircraft for which the low-g duration is approximately $20 \mathrm{sec}$ and (2) all low-g studies have been performed using small-scale laboratory configurations. Demonstration of low-g fire suppression at realistic scales is practically essential for final evaluation of a fire suppression system.

To address the lack of fire extinction data in an extended low-gravity environment, the Flame Extinguishment Experiment (FLEX) will be conducted in the Multi-User Droplet Combustion Apparatus (MDCA) in the Combustion Integrated Rack (CIR) on the ISS. This experiment will provide unique low-gravity data on the extinction effectiveness and mechanisms of several gaseous fire suppressants using a droplet geometry for which 
some of the complex extinction processes can be elucidated. The critical Damköhler number will be extracted from the flame properties and droplet diameter at the time of extinction and used to relate data between the droplet and other configurations. The Limiting Oxygen Index (LOI) will also be measured as a function of pressure and oxygen concentration to determine the lowest $\mathrm{O}_{2}$ concentration that will sustain a low-gravity flame. Detailed simulations of the combustion process made possible by this data will be used to produce simplified models of combustion kinetics that can be used in the large-scale simulations of fire scenarios to be discussed in Section C.3. While the FLEX project is being conducted under the ISS Research Project instead of the FPDS project, the data will greatly add to our knowledge of low-gravity fire suppression and improve the quality and applicability of the product in Deliverable 6. The MDCA and CIR hardware is scheduled to launch to the ISS on ULF-2 in July 2008.

A critical step in understanding low-g fire suppression is to reconcile the results of studies performed to date that have made use of various configurations, fuels, suppressant agents, and gravity levels. This effort was begun in a trade study on low-g fire suppression that was performed in FY06. This study reviewed existing data and evaluated the effectiveness of various agents for fire suppression in the CEV. As more data is obtained and documented, the results will be expanded and used not only in trade studies of fire suppressants for CEV and LSAM but also to indicate specific knowledge gaps that must be filled by additional testing, analysis, or modeling.

\section{Suppressant Dispersion Methods (Deliverable 5)}

The objective of this task is to characterize the large-scale deployment of a suppressant in low-gravity. As expected, investigation of the dispersion method presumes that the suppressant has been selected. Also, it is very difficult to perform useful dispersion experiments on small scale geometries because of the dependence of the injection and mixing phenomena on scale, especially if a liquid or foam suppressant is used. We anticipate that once a fire suppressant system for CEV is selected, tests or numerical simulations can be conducted to investigate its dispersion characteristics in low- and reduced gravity. In the interim, tasks in this area involve limited experiments and numerical simulations of gaseous suppressant dispersion. Because gaseous $\mathrm{CO}_{2}$ was used as the suppressant agent on the U.S. modules of the ISS, simulations have been performed of $\mathrm{CO}_{2}$ dispersion in the CIR and compared with experimental measurements. Researchers are developing computational models of the early CEV designs to use in both these simulations and those required to model contaminant transport, as discussed in Section B.3 (PI: Dr. D. P. Stocker, NASA GRC).

\section{Evaluation of Spacecraft Fire Suppression (Deliverable 3 and 5)}

The evaluation of spacecraft fire suppression systems requires the melding of the technologies developed by the definition of fire scenarios, modeling of smoke and contaminant transport and detection (Section B.3), knowledge of fire suppressant effectiveness (experiment and modeling) (Section C.1), and verified simulations of suppressant dispersion (Section C.2). This task will use all of the applicable tools developed in this project to evaluate the effectiveness of the detection and suppression systems to respond to a credible fire source. Because of the number of variables involved, this analysis is only meaningful if actual geometry, credible fire sources, and anticipated ventilation characteristics are used. However, the more comprehensive a numerical simulation is required to be, the more it becomes tailored to that specific configuration and set of conditions. Codes tailored for terrestrial analyses are not directly applicable to spacecraft without preliminary assessment and, in some cases, extensive modification. Several grants were begun in the Spacecraft Fire Safety program that have been investigating how to apply tools developed for terrestrial fire analysis, specifically in buildings and on board ships, to spacecraft applications. These efforts include "Large-Scale Fire Dynamics in Spacecraft in Reduced Gravity" (PI: Dr. G. Linteris, National Institute of Standards and Technology), "Fire Suppression and Safety in reduced Gravity Environments" (co-I: Drs. K. Kailasanath and D. Schwer, Naval Research Laboratory), and "Development of an Engineering Tool for the Determination of Suppression Device Placement in Reduced Gravity Environments" (PI: Dr. R. Roby, Combustion Science and Engineering, Inc.). These grants have received their final funding and will be completing work in FY07. As the FPDS tasks develop and the design of the CEV solidifies, formal tasks in this area will be defined. The approach will be two-pronged, i.e., analysis tasks that directly support Orion and tasks that incorporate and the FPDS deliverables will be incorporated into specific tools

\section{Conclusions}

The Fire Prevention, Detection, and Suppression project is a technology development effort that addresses all aspects of fire safety aboard crewed exploration systems. This paper has identified the six deliverables for this FPDS project that are in the form of hardware, software, and/or information (e.g., data libraries). Even though they were formulated prior to the announcement of the VSE, these deliverables have remained essentially intact because they 
address NASA's basic philosophy for preventing fires on spacecraft. It is anticipated that they will continue to remain relevant throughout the exploration missions. The status, accomplishments and plans for each of the major tasks within the FPDS project were also presented in this paper. The teams of scientists and technicians that are conducting these tasks provide NASA's primary expertise in reduced gravity fire behavior as well as fire detection and suppression. These technologies play a very important role in the implementation of the Vision for Space Exploration.

In addition to performing the tasks identified in the FY07 FPDS Integrated Baseline Review and summarized in this paper, a primary activity in the coming year will be to infuse these technologies into the Constellation and CEV requirements and designs. This will be done both by working with the Exploration Technology Development Program Office and, more importantly, with NASA and contractor CEV designers. Throughout the on-going design of the CEV and the LSAM to follow, the most critical aspects of the FPDS project will be to (1) continue to make progress on all of the deliverables so that they can be infused into the CxP when needed, (2) be responsive to the NASA and contractor CEV development team as their designs progress and (3) participate in NASA-wide working groups and standard development activities to have input to the design and operational requirements for exploration habitats and vehicles. Undoubtedly, budget and technical challenges will continue but, similar to NASA's implementation of the VSE, the personnel in the FPDS project will adjust to continue to deliver relevant fire safety technologies to the exploration mission.

\section{Acknowledgments}

The authors would like to acknowledge the efforts of all of the individuals who are conducting and assisting the tasks that make up the FPDS project. Of particular note are Dr. Fletcher J. Miller (NCSER) and Dr. Daniel L. Dietrich (NASA GRC), the Leads for the Material Flammability Research Team and the Fire Suppression and Response Research Team, respectively. Their effort and dedication contribute greatly to the definition, formulation, and performance of each of the tasks described in this paper. Their help in leading this project is greatly appreciated.

\section{References}

${ }^{1}$ Urban, D. L. and King, M. K. “NASA’s Microgravity Combustion Research Program: Past and Future,” Comb. and Flame, Vol. 116, No. 3, February 1999.

${ }^{2}$ Ruff, G. A., Urban, D L., and King, M. K. “A Research Plan for Fire Prevention, Detection, and Suppression in Crewed Exploration Systems,” AIAA-2005-0341, 43 ${ }^{\text {rd }}$ AIAA Aerospace Sciences Meeting and Exhibit, Reno, NV, January 10-13, 2005.

${ }^{3}$ Ruff, G. A., Urban, D L., and King, M. K. "Fire Prevention, Detection, and Suppression Research Supporting Manned Space Exploration - One Year Later,” AIAA-2005-0347, 44 ${ }^{\text {th }}$ AIAA Aerospace Sciences Meeting and Exhibit, Reno, NV, January 912, 2006.

${ }^{4}$ Ruff, G. A. (ed.), Research Needs in Fire Safety for the Human Exploration and Utilization of Space: Proceedings and Research Plan, NASA CP-2003-212103, April 2003.

${ }^{5}$ Sacksteder, K. (ed.), Seventh International Workshop on Microgravity Combustion and Chemically Reacting Systems, NASA CP-2003-212376, June 2003.

${ }^{6}$ Margle, J. M. (ed.), Spacecraft Fire Safety, NASA CP-2476, August 1987.

${ }^{7}$ Apostolakis, G. E., Catton, I., Paulos, T., Paxton, K., and Jones, S., "Findings of a Review of Spacecraft Fire Safety Needs," NASA CR-189181, 1992.

${ }^{8}$ Youngblood, W. N. and Vedha-Nayagam, M., “Advanced Spacecraft Fire Safety: Proposed Projects and Program Plan,” NASA CR-185147, 1989.

${ }^{9}$ Reuther, J. J., “Definition of Experiments to Investigate Fire Suppressants in Microgravity,” NASA CR 185295, 1990.

${ }^{10}$ National Aeronautics and Space Administration Technical Standard 6001, "Flammability, Odor, Offgassing, and Compatiblity Requirements and Test Procedures for Materials in Environments That Support Combustion”, 1998.

${ }^{11}$ Cordova, J. L., Walther, D. C., Fernandez-Pello, A. C., Steinhaus, T., Torero, J.L., Quintiere, J. G., and Ross, H. D., “Flow Effects on the Flammability Diagrams of Solid Fuels: Microgravity Influence on Ignition Delay,” in Sacksteder, Kurt, ed.: Fifth International Microgravity Workshop. NASA/CP-1999-20817, May 1999, pp. 35-38.

${ }^{12}$ Olson, S. L., Beeson, H., and Haas, J. P., “An Earth-Based Equivalent Low Stretch Apparatus to Assess Material Flammability for Microgravity and Extraterrestrial Fire-Safety Applications,” Seventh International Workshop on Microgravity Combustion and Chemically Reacting Systems, NASA CP-2003-212376, June 2003, pp. 213-216.

${ }^{13}$ Incropera, F. P. and DeWitt, D. P. Fundamentals of Heat and Mass Transfer, John Wiley \& Sons, New York, 1990.

${ }^{14}$ Olson, S. L., Miller, F. J., and Wichman, I. S., “Characteristics of the Flamelet Regime of Flame Spread”, 4th Joint Meeting of the U.S. Sections of the Combustion Institute, Drexel University, Philadelphia, PA, March 20-23, 2005.

${ }^{15}$ Quintiere, J. G. “A Theoretical Basis for Flammability Properties,” Fire Mater. Vol. 30, 2006, pp. 175-214.

${ }^{16}$ Tewarson, A. "Generation of Heat and Chemical Compounds in Fires," The SFPE Handbook of Fire Protection Engineering ( $3^{\text {rd }}$ ed). Section 3, Chapter 4. The National Fire Protection Association Press: Quincy, MA 2002, pp. 3-161. 
${ }^{17}$ NASA Marshall Space Flight Center (MSFC) Materials and Processes Technical Information System (MAPTIS), http://maptis.nasa.gov; also, MSFC-HDBK-527/JSC 09604.

${ }^{18}$ Olson, S. L. "Mechanisms of Microgravity Flame Spread Over a Thin Solid Fuel: Oxygen and Opposed Flow Effects," Comb. Science and Tech., Vol. 76, 1991, pp. 233-249.

${ }^{18}$ Feier, I. I., Kleinhenz, J., T’ien, J. S., Ferkul, P. V., and Sacksteder, K. R., "Pressure Modeling of Upward Flame Spread Rates in Partial Gravity,” $43^{\text {rd }}$ AIAA Aerospace Sciences Meeting and Exhibit, AIAA-2005-0716, January 2005, Reno, NV.

${ }^{20}$ Kleinhenz, J.E. "Flammability and Flame Spread of Nomex and Cellulose in Space Habitat Environments," Ph.D. Dissertation, Case Western Reserve University, May 2006.

${ }^{21}$ Lange, K. E., Perka, A. T., Duffield, B. E., and Jeng, F. F. "Bounding the Spacecraft Atmosphere Design Space for Future Exploration Missions,” NASA CR-2005-213689, 2005.

${ }^{22}$ Olson, S .L., Ferkul, P. V., and T’ien, J. S., “Near-Limit Flame Spread Over a Thin Solid Fuel in Microgravity,” TwentySecond International Symposium on Combustion, The Combustion Institute, pp. 1213-1222.

${ }^{23}$ Urban, D. L., Griffin, D., Ruff, G. A., Cleary, T., Yang, J., Mulholland, G., and Yuan, Z.-G. "Detection of Smoke from Microgravity Fires,” Paper No. 2005-01-2930, 35 ${ }^{\text {th }}$ International Conference on Environmental Systems, Rome, Italy, July 11-14, 2005.

${ }^{24}$ Hamins, A., Bundy, M., Puri, I. K., McGrattan, K., and Park, W. C., "Suppression of Low Strain Rate Nonpremixed Flames by an Agent,” NASA CP-2001-210826, 2001, pp. 101-104.

${ }^{25}$ Katta, V. R., Takahashi, F., and Linteris, G. T., "Suppression of Cup-Burner Flames Using Carbon Dioxide in Microgravity,” Combustion and Flame, Vol. 137, 2004, pp. 506-522.

${ }^{26}$ Takahashi, F., Linteris, G. T., and Katta, V. R., "Suppression Characteristics of Cup-Burner Flames in Low Gravity," AIAA-2004-0957, 42 ${ }^{\text {nd }}$ AIAA Aerospace Sciences Meeting and Exhibit, Reno, NV, January 2004.

${ }^{27}$ Takahashi, F., Linteris, G. T., and Katta, V. R., "Extinguishment Mechanisms of Cup-Burner Flames in Low Gravity," AIAA-2006-0745, 44 ${ }^{\text {th }}$ AIAA Aerospace Sciences Meeting and Exhibit, Reno, NV, January 2006.

${ }^{28}$ Ruff, G. A., Hicks, M., and Pettegrew, R., “Assessment of $\mathrm{CO}_{2}, \mathrm{~N}_{2}$, and He as Suppressant Agents in Microgravity,” Spring Meeting of the Western States Section/The Combustion Institute, Davis, CA, March 2004. 